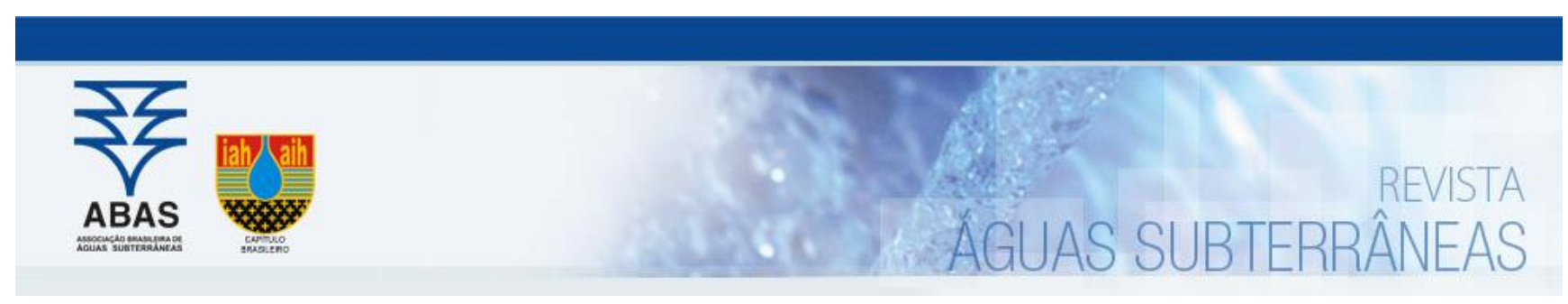

Artigos

\title{
Balanço hídrico transitório do aquífero Urucuia meridional na Bahia
}

\section{Transient water balance of the Southern Urucuia aquifer in Bahia}

\author{
Leanize Teixeira Oliveira,1,2; Harald Klammler3; Luiz Rogério Bastos Leal ${ }^{\circledR}$ \\ 1 Serviço Geológico do Brasil, Salvador, BA \\ 3 Instituto Federal da Bahia (IFBA), Salvador, BA \\ 3 Universidade Federal da Bahia (UFBA), Salvador, BA \\ $\bowtie$ leanize.oliveira@cprm.gov.br, haki@ufl.edu, Irogerio@ufba.br
}

Palavras-chave:

Aquífero Urucuia.

Simulação Transiente.

Análise Isotópica.

\begin{abstract}
Resumo
A mensuração dos componentes do balanço hídrico de uma bacia do ponto de vista temporal e espacial é extremamente relevante na gestão dos recursos hídricos e no entendimento das flutuações de niveis da água subterrânea. 0 aquífero Urucuia vem sendo monitorado por dataloggers instalados em poços dedicados que mostram um declínio contínuo nos níveis d'água atingindo até $1,1 \mathrm{~m} /$ ano. Foi realizada a análise isotópica em conjunto com a simulação numérica de fluxo em estado estacionário e transiente na porção meridional do aquífero Urucuia-Bahia (23\% da área aflorante total) para descrever a dinâmica dos componentes do balanço hídrico entre 2005 e 2018. A análise isotópica evidencia a interação rio-aquífero e o efeito da evapotranspiração na recarga. Os resultados mostram diminuição progressiva da recarga entre 2012 e 2017, sendo fortemente influenciada pela evapotranspiração e diminuição das chuvas, causando o declínio nos níveis d'água subterrâneos e do fluxo de base dos rios, também influenciado pelo bombeamento dos poços. Adicionalmente o modelo numérico foi desenvolvido para gerar respostas degrau a uma diminuição de recarga em $10 \%$ mostrando que cargas hidráulicas e fluxos de base tardam aproximadamente uma década para se reequilibrarem. Os resultados evidenciam a importância de monitoramento hidroclimatológico contínuo e mensuração das retiradas, visando acompanhar a dinâmica entre demandas e disponibilidades hídricas.
\end{abstract}

\begin{abstract}
Quantification of the temporally and spatially variable water balance components in a catchment is extremely relevant for the management of water resources and the understanding of fluctuations in groundwater levels. The Urucuia aquifer has been monitored by dataloggers installed in dedicated wells and shows a continuous decline in water levels reaching up to $1.1 \mathrm{~m} /$ year. Isotopic analysis was performed in conjunction with steady-state and transient flow simulation in the southern portion of the Urucuia aquifer ( $23 \%$ of total area) to describe the dynamics of the water balance components between 2005 and 2018. The isotopic analysis were fundamental for the construction of the conceptual model indicating river-aquifer interaction and the effect of evapotranspiration on recharge. Results show that recharge decreased progressively between 2012 and 2017, being strongly influenced by evapotranspiration and diminishing rainfall, causing a decline in groundwater levels and river base flows, also influenced by pumping wells. The numerical model was further used to compute step responses to a $10 \%$ drop in recharge, indicating that hydraulic heads and river base flows re-equilibrate after approximately one decade. It is highlighted that continuous hydroclimatological monitoring and withdrawals measurements to observe the dynamics between water demands and availability are important.
\end{abstract}

DOI:http:/dx.doi.org/10.14295/ras.v34i3.29915

\section{INTRODUÇÃO}

Altas demandas de água da população estão conduzindo a depleção de aquíferos em muitos locais do planeta (LE BROCQUE et al., 2018; WADA, 2016). Werner et al. (2013) comparou os casos de declínio dos níveis d'água em diversos aquíferos e considerou que os cinco maiores casos de depleção estão na Planície do rio Hai-China, Altiplano-Espanha, Bacia do MéxicoMéxico, Bacia do rio Huang-China e Vale Central da CalifórniaEUA, com declínios variando entre 1-10m/ano. No Brasil, o mesmo estudo cita apenas o aquífero Guarani ocupando o qua- dragésimo lugar no ranking.

A depleção é conceituada como declínio a longo prazo no armazenamento de água subterrânea e pode gerar efeitos indesejáveis como a subsidência do solo, intrusão de água salina em aquíferos costeiros, seca de fontes, redução de vazão de cursos d'água, desaparecimento de nascentes de rios, desequilíbrio de ecossistemas ribeirinhos e alterações na qualidade da água. Outra consequência é a necessidade de aprofundamento dos poços para captação de água que se reverte em um custo maior para perfuração e bombeamento. 
Sob condições naturais, sem bombeio, os aquíferos estão em estado de equilíbrio dinâmico, com a taxa média de recarga natural igual à taxa média de descarga natural. Desequilíbrios temporários tendem a se reequilibrar após um ciclo climático, com diminuição da descarga natural e/ou perdas no armazenamento e/ou variações na recarga. No entanto, descargas adicionais contínuas (e.g. extração por poços) levam o sistema hídrico a equilíbrios diferentes implicando diminuição da descarga natural e/ou perdas no armazenamento (THEIS, 1940).

Localmente, o bombeamento induz um gradiente hidráulico na direção do poço, formando o cone de depressão no seu entorno, com componentes horizontais e verticais de fluxo (em aquíferos livres). Com a continuidade do processo, o cone migra e uma porção maior do aquífero estará contribuindo com água para o poço, até atingir zonas de descarga ou recarga, alterando assim o seu comportamento (FETTER, 2001). A geometria e dinâmica desse cone dependem das características físicas do meio, presença de barreiras hidráulicas, taxas de bombeamento e afastamento entre os poços, caráter da recarga, e distância dos poços ao local de descarga natural.

A explotação em períodos curtos é mais dependente das propriedades hidráulicas do aquífero e da disposição geométrica dos campos de poços, mas para períodos mais longos a natureza dos contornos do sistema hídrico controla a produção dos aquíferos (FREEZE e CHERRY, 1979). As flutuações dos níveis de água (NA) subterrâneos são o resultado de processos como mudanças do volume de água armazenada no aquífero (recarga por infiltração de chuva e rios, influência de poços vizinhos, áreas de irrigação), mudanças na pressão atmosférica e mudanças causadas por deformação do aquífero (efeitos de maré ou terremotos). Alguns autores consideram que a explotação de aquíferos deve ser norteada pela sustentabilidade ambiental do sistema hídrico no sentido de equilibrar as condições de bombeio à mitigação de suas consequências (MAlMONE, 2004; ZHOU, 2009; CHAMINÉ, 2015).

A investigação da dinâmica do NA subterrâneo e a quantificação dos componentes do Balanço Hídrico (BH), considerando inclusive as saídas artificiais por bombeio de poços, é complexa e fundamental para evitar subjetividades na análise da sustentabilidade do uso dos recursos hídricos. Na literatura encontram-se estudos baseados em modelos matemáticos com soluções analíticas ou numéricas (FISHER et al., 2016; OU et al., 2018), além de redes neurais (GUZMAN et al., 2017; MOHANTY et al., 2013) que investigam aspectos como as relações entre água subterrânea, água superficial, disponibilidades hídricas, variabilidades da recarga, entre outros.

Dentro desse contexto, a modelagem de aquíferos visando simulação de fluxo transitório é uma ferramenta extremamente válida, pois permite avaliar o balanço de volume d'água do sistema em seus diversos componentes baseado em princípios físicos e de forma espacialmente distribuída.

No Brasil, um dos principais problemas para análises tempo- rais de sistemas hídricos subterrâneos está relacionado à base de dados históricos que costuma ser escasso e não sistemático. Contudo, na região Oeste da Bahia, o aquífero Urucuia vem sendo monitorado pela CPRM-Serviço Geológico do Brasil por meio de 62 poços dedicados (em toda a sub-bacia Urucuia) que acompanham as variações de NA desde 2011 e apresentam rebaixamento médio de $2,5 \mathrm{~m}$, com valores máximos de $6,67 \mathrm{~m}$ desde o início da implantação da rede.

Neste artigo foi utilizada a simulação estacionária e transiente de fluxo de água subterrânea em aquífero intergranular submetido à explotação por poços, e de forma complementar a interpretação de assinaturas isotópicas de ${ }^{18} \mathrm{O}, 2 \mathrm{H}$ e ${ }^{3 \mathrm{H}}$, com o objetivo de analisar a dinâmica de flutuações do NA e avaliar as variações temporais dos componentes do $\mathrm{BH}$ em uma porção do Sistema Aquífero Urucuia (SAU).

0 modelo conceitual adotado demonstra-se bem ajustado à simulação de fluxo, permitindo avaliar de forma espacial e temporal as variações mensais dos componentes do $\mathrm{BH}$ e sua relação com as variações de NA, evidenciando a influência dos mecanismos de recarga e da explotação do aquífero.

\section{2. ÁREA DE ESTUDO}

\subsection{Hidrografia e Ocupação}

A área de estudo compreende as bacias hidrográficas dos rios Arrojado, Formoso e Éguas, afluentes do rio Correntina no Oeste da Bahia, em uma área de aproximadamente $20.000 \mathrm{~km}^{2}$. A área modelada numericamente inclui a maior parte da área estudada, limitando-se a oeste pelo divisor de águas subterrâneas e a leste pelo contato Urucuia/cristalino (Figura 1A). Trata-se de um Chapadão de topo plano, com elevações variando entre 470 e $1016 \mathrm{~m}$, onde drenagens de padrão paralelo a sub-paralelo se instalam não apresentando grandes desníveis.

A região, tipicamente agrícola, apresenta uma vegetação nativa do tipo Cerrado e áreas de lavoura, muitas vezes irrigadas por pivôs nas porções planas do Chapadão. Nas porções ribeirinhas dos vales encaixados dos rios principais e afluentes predominam matas de galeria e veredas, além de áreas antropizadas com o pasto e pequenos povoados ribeirinhos. As imagens temporais de satélite mostram uma supressão de aproximadamente $55 \%$ da vegetação natural nos últimos 31anos (tomando como base imagens de satélite entre 1988 e 2019; Figuras $1 \mathrm{~A}$ e $1 \mathrm{~B})$.

Até 1955 a região tinha pouca expressividade econômica prevalecendo a criação bovina e plantação de arroz nas regiões ribeirinhas. Na década de 80 , inicia-se a ocupação das áreas do chapadão em grandes propriedades. A partir da década de 90, a região transforma-se em um grande eixo produtor do estado com agricultura mecanizada e lavoura irrigada por pivôs (Figura 1A). Atualmente a atividade agrícola cresce continuamente. 
Figura 1 - (A) Mapa de localização da área estudada e área modelada, estações fluviométricas e pivôs. (B) Imagens de Satélite de jul/1988 a jul/2019, realçando a lâmina d'água e áreas úmidas da Lagoa do Pratudão e entorno (linha branca evidencia regressão da lâmina d'água)

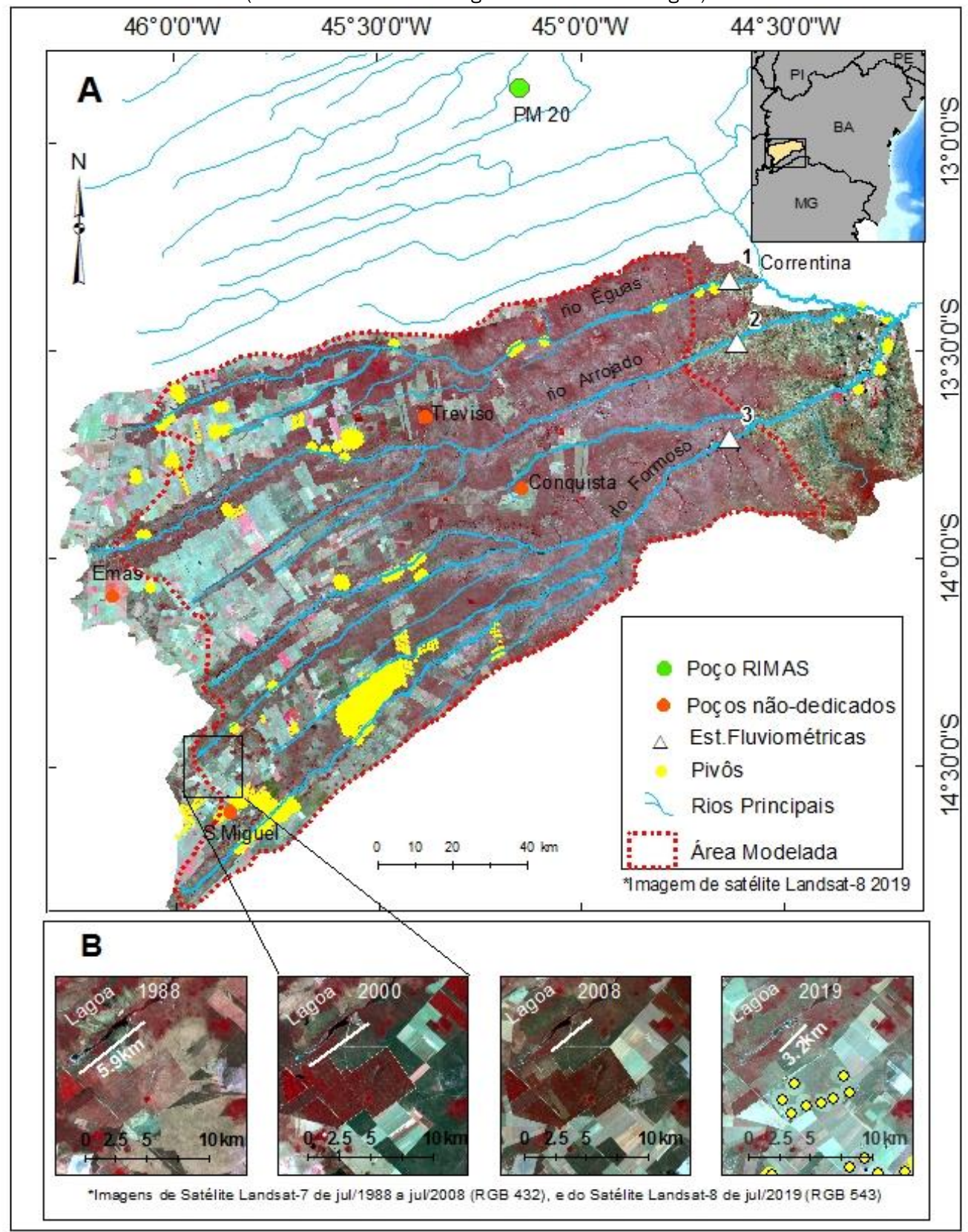

O avanço econômico tem sido proporcional ao aumento da demanda de água. Dados de outorgas subterrâneas (aquífero Urucuia) e superficiais (principalmente nas sub-bacias Arrojado e Formoso) indicam demandas por poço variando de 4 a $500 \mathrm{~m}^{3} / \mathrm{h}$, em regime de até $18 \mathrm{~h} / \mathrm{dia}$, totalizando $1,74 \mathrm{~m}^{3} / \mathrm{s}$ outorgados e em análise em 2018 , tendo por finalidade principalmente a irrigação e abastecimento humano/animal. Entre os 406 poços cadastrados na área (dos quais 336 encontram-se na área modelada) apenas $14 \%$ destinam-se à irrigação, mas representam $89,3 \%$ do volume total demandado. A somatória das taxas de bombeio de poços na área em 2017 foi de 4,61 m³/s (OLIVEIRA et al., 2019). Entre 2005 e 2017, alguns poços de produção foram acompanhados com regis- tros não sistemáticos e não contínuos de NA, utilizando-se medidores de nível manual, onde se observa uma tendência de declínios contínuos aproximadamente, a partir de 2012 (Figura 2A) e oscilações entre períodos de rebaixamento e recuperação nos poços Treviso e Conquista. As vazões médias dos rios também vêm sofrendo declínio (Figura 2B), sendo um reflexo das ações conjuntas de diminuição de fluxo de base (OLIVEIRA et al., 2019) e retiradas diretas de águas para irrigação. Alterações significativas nas nascentes, a exemplo da Lagoa do Pratudão, podem ser vistas na análise temporal de imagens de satélite da região onde estima-se um recuo de $2,7 \mathrm{~km}$ entre 1988 e 2019, apesar de não ocorrer retiradas diretas de água na lagoa (Figura 1B). 
Figura 2 - (A) Rebaixamentos de NA em poços não-dedicados entre 2005-2019; (B) Médias mensais (Q) da somatória de vazões dos rios Éguas(1), Arrojado(2) e Formoso(3), fonte: ANA (2020). Ver Figura 1A

Ano
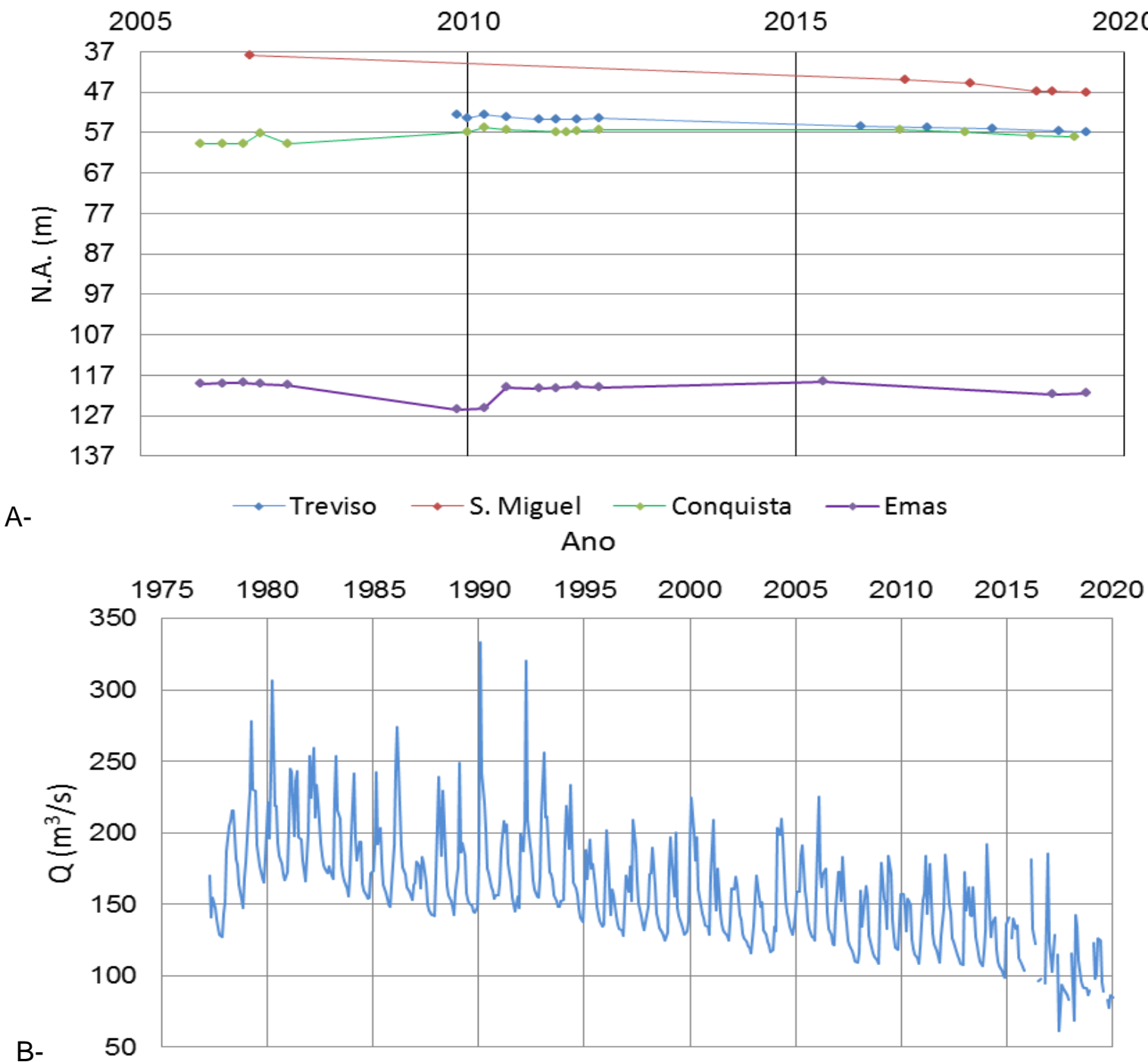

\subsection{Hidrogeologia}

O aquífero Urucuia estende-se do norte de MG ao sul do PI, na bacia Sanfranciscana, sendo que a área aflorante apresentase de forma contínua na porção centro norte e acompanha toda a extensão da bacia. Tem sido utilizado o termo SAU para descrever o aquífero regional Urucuia composto por quatro subtipos de aquíferos (livre regional, livre profundo, suspenso ou confinado/semi-confinado) (GASPAR, 2006). O Grupo Urucuia engloba as unidades litoestratigráficas das formações Posse e Serra das Araras, constituídas por arenitos muito finos, finos e médios por vezes ocorrendo níveis conglomeráticos e lentes descontínuas silicificadas. Nos poços de monitoramento (PMs) do Serviço Geológico do Brasil (SGB), na área de estudo, os perfis litológicos são essencialmente arenosos de granulometria fina a média com níveis de até $20 \mathrm{~cm}$ de espessura de arenito silicificado, não apresentando níveis argilosos ou cascalhosos identificáveis nas amostras de calha. Os níveis silicificados descontínuos e não mapeáveis na escala de trabalho podem conferir localmente características de aquífero suspenso ou semi-confinamento.

A espessura do Grupo Urucuia na área varia entre 35 e 535m e foi levantada a partir de modelagem geológica (OLIVEIRA et al., 2019). Valores de porosidade efetiva (Sy) de $14 \%$ e $17 \%$, transmissividade $(\mathrm{T})$ de $4,1 \times 10^{-2} \mathrm{~m}^{2} / \mathrm{s}$ e $1,6 \times 10^{-2} \mathrm{~m}^{2} / \mathrm{s}$, coefici-

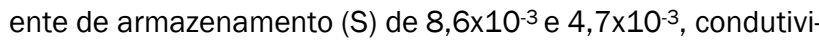
dade hidráulica horizontal $(\mathrm{K})$ de $1,7 \times 10^{-4} \mathrm{~m} / \mathrm{s}$ e $6,9 \times 10^{-5} \mathrm{~m} / \mathrm{s}$, e condutividade hidráulica vertical de $1,4 \times 10^{-4} \mathrm{~m} / \mathrm{s}$ e $8,1 \times 10$ $5 \mathrm{~m} / \mathrm{s}$ foram obtidos em dois testes de aquífero realizados na área (CPRM, 2008). Transmissividades calculadas em 15 poços a partir do método de recuperação de Jacob mostram também valores da ordem de $10^{-2} \mathrm{~m}^{2} / \mathrm{s}$. Os níveis estáticos (NEs) são em geral profundos ( $>30 \mathrm{~m})$, exceto nas áreas próximas às drenagens. Existe uma assimetria em relação ao eixo divisor de águas subterrâneas que ocorre no sentido N-S (CPRM, 2008), sendo que os NEs a oeste podem chegar a $177 \mathrm{~m}$ de profundidade, de acordo com dados próprios levantados em campo. 


\subsection{Clima}

O clima é classificado como tropical, de inverno seco, com pluviosidade que diminui de oeste para leste e no sentido nortesul com valores variando entre 1200 e $600 \mathrm{~mm}$ /ano. Períodos chuvosos são bem definidos: valores máximos mensais ocorrem no período de novembro a maio, e os mínimos de junho a outubro. A temperatura do ar varia de $3^{\circ}$ a $38^{\circ} \mathrm{C}$, com média de $22^{\circ} \mathrm{C}$ e umidade relativa variando de $10 \%$ a $94 \%$, com média de $58 \%$.

Estudo hidroclimático identificou uma diminuição de 12\% das chuvas na bacia do rio Corrente a partir de 1980 (POUSA et al., 2019). A tendência de declínio das chuvas na região do aquífero Urucuia é observada em séries históricas mais curtas, sendo que nas séries mais longas observam-se déficits anuais semelhantes aos atuais, ocorridos nas décadas de 1940 e 1950, (CPRM, 2019),

$\mathrm{Na}$ área de estudo, a série histórica claramente evidencia a variabilidade intra e interanual das chuvas e o período mais seco e com menor variabilidade interanual a partir de 2012/2013 a 2018, semelhante ao ocorrido na década de 1970, e com tendência de aumento das chuvas a partir de 2019/2020 (Figura 3).

Figura 3 - Gráfico de chuvas mensais (P) e média de chuvas total anuais entre 1973-2019 (ver estações na Figura 6)

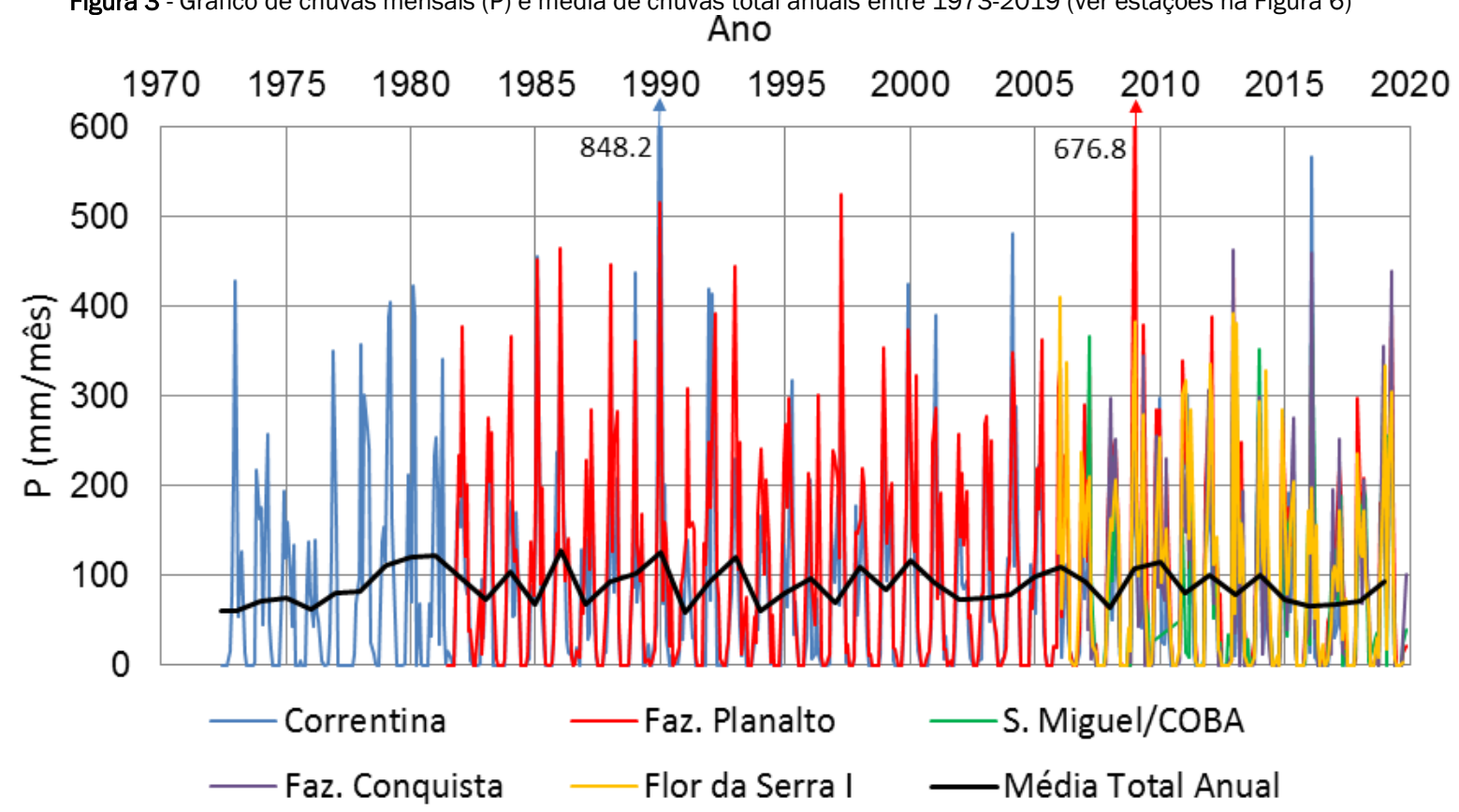

\section{MATERIAIS E MÉTODOS}

\subsection{Obtenção dos Dados de Poços}

Foram utilizados perfis litológicos/construtivos de 406 poços tubulares, além de informações de campo obtidas pelos autores in loco ou disponíveis no banco de dados do SGB (SGBCPRM, 2020). Os consumos diários de água dos poços foram obtidos através dos dados de outorga, informações in loco nas fazendas ou foram estimados em função do uso e ocupação do solo, por semelhanças com outros pontos conhecidos e identificados. Deve-se observar que a estimativa do consumo total diário em uma área de grandes dimensões como a área de estudo, só foi possível em função da relativa homogeneidade das atividades sociais e econômicas e da realização de cadastro in loco entre 2015 e 2017 abrangendo grande parte das propriedades. Entretanto, destaca-se que as captações geralmente não apresentam hidrômetros instalados.

Os poços monitorados fazem parte da Rede Integrada de Monitoramento de Águas Subterrâneas (RIMAS/SGB) e apresentam características construtivas semelhantes (diâmetro de
41/2", 4 a 16 m de filtros e profundidade total de $40 \mathrm{~m}$ abaixo do nível estático). Nas bacias hidrográficas estudadas, existem onze PMs com dataloggers instalados entre dezembro/2015 e julho/2016, tendo sido utilizados oito deles para calibração do modelo por estarem inseridos na área modelada.

\subsection{Coleta e Análise Isotópica de Águas}

Estudos de interpretação da assinatura isotópica são feitos visando auxiliar na construção do modelo conceitual e entender a dinâmica da recarga das águas subterrâneas. Foram realizadas análises de isótopos ambientais de Oxigênio (180) e Deutério ( $\left.{ }^{2} \mathrm{H}\right)$, em 2005/2006 (CPRM, 2008) e em 2016 da seguinte forma: i) amostras de águas de rios em 26 pontos por duas amostragens em 2016 e mais 5 pontos em três amostragens em 2005/2006; ii) até 37 poços amostrados em três campanhas em 2005/2006 e 23 poços amostrados em 2015/2016; iii) Uma amostra de lagoa em 2016 e iv) uma amostra de chuva coletada em um evento diário no pluviômetro do tipo convencional, modelo DNAEE, em 2006 e, seis 
amostras coletadas em duas campanhas em 2016, em coletor adaptado de Gröning et al. (2012). Três amostras de chuva foram descartadas, pois sofreram fracionamento no reservatório. As amostras de água subterrânea estão associadas às formações Serra das Araras e Posse. Além dos isótopos ambientais, o isótopo radiogênico Trítio $\left({ }^{3} \mathrm{H}\right)$ foi analisado para águas de rio (3) e poços (5) visando uma interpretação qualitativa da recarga.

As análises de isótopos estáveis foram realizadas no Laboratório de Física Nuclear da Universidade Federal da Bahia, utilizando-se espectrômetro de massa com reator automático específico para as análises $\mathrm{D} / \mathrm{H}$, e um sistema de preparação automática de amostras on-line específico para análise de ${ }^{180} \mathrm{O}$. As análises de ${ }^{3} \mathrm{H}$ foram realizadas no Laboratório de Trítio Ambiental do Centro de Desenvolvimento da Tecnologia Nuclear-CDTN, utilizando Enriquecimento Eletrolítico e Contagem em Cintilador Líquido (de acordo com a NBR ISO/IEC 17025:2001).

\subsection{Modelo Numérico}

Foi adaptado um modelo tridimensional de simulação de fluxo subterrâneo, baseado no método numérico de diferenças finitas, utilizando o software MODFLOW (HARBAUGH et al., 2005) com os pacotes computacionais MODPATH e ZONEBUDGET, na versão comercial VisualModflow4.1.

O modelo conceitual considera que o sistema hidrogeológico Urucuia na área modelada é do tipo livre regional, sendo as formações Posse e Serra das Araras uma única unidade hidroestratigráfica, com homogeneidade regional, ou seja, não foram consideradas na escala adotada as porções localizadas de confinamento/semi-confinamento. As águas subterrâneas estão em conexão hidráulica com os rios e não há perdas ou ganhos do fluxo subterrâneo para as unidades litoestratigráficas adjacentes, conforme sugerido pelas assinaturas isotópicas e análise hidrogeológica. Admite-se ainda o divisor de águas subterrâneas localizado a Oeste como fluxo nulo, assim como os divisores de bacia hidrográfica localizados a norte e sul. A saída de água do aquífero ocorre unicamente pelos rios (Figura 4).

Figura 4 - Representação do modelo conceitual. Bloco Diagrama com geologia simplificada e seção vertical esquematizada
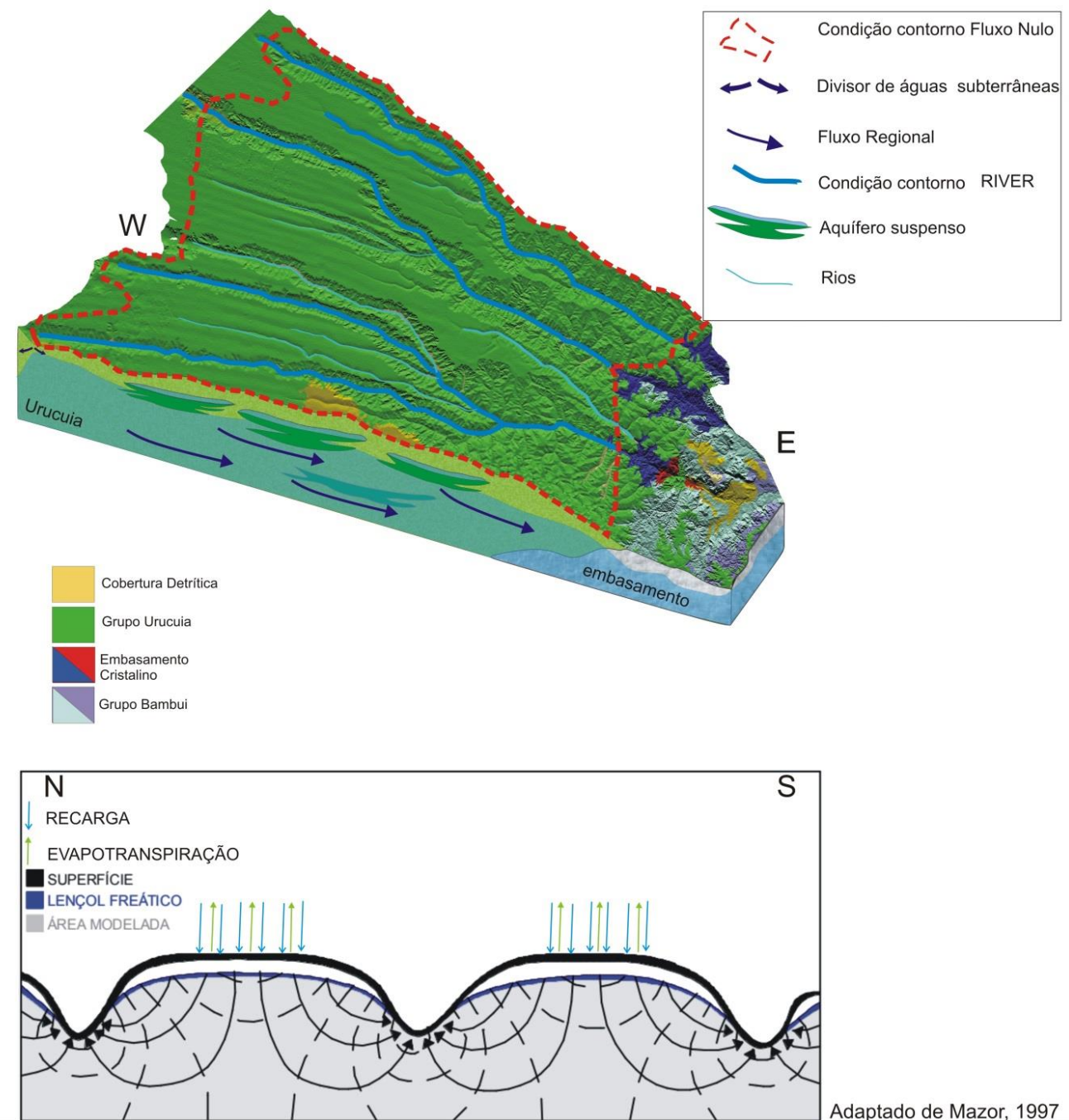

As condições de contorno utilizadas foram dos tipos: i) Imper-

nos divisores de bacias hidrográficas a Norte e Sul, no divisor meável (Newman) em todo o contorno externo do modelo (i.e. 
o embasamento cristalino a leste, Figura 1A e 4, ii) Fluxo dependente da carga hidráulica (Cauchy) representado pela opção "River" nos principais afluentes dos rios Éguas, Arrojado e Formoso. Assim, a condição de contorno "River" simula a influência de corpos d'água superficiais sobre o fluxo de água subterrânea e se admite que o valor da carga no modelo, em cada ponto de um rio, permanece fixo no nível especificado. A área modelada foi discretizada em 177 linhas e 210 colunas, resultando em cerca de 16000 células ativas de $1000 \mathrm{x}$ $1000 \mathrm{~m}$.

Inicialmente a simulação de fluxo foi feita em estado estacionário objetivando calibrar parâmetros, gerar as cargas hidráulicas iniciais da simulação transiente, efetuar o balanço numérico de massa e ajustar as elevações dos rios à topografia. A calibração do modelo foi feita pelo método da tentativa e erro e posteriormente foi utilizado o pacote PEST de calibração automática (para que os resultados fossem melhor avaliados já que a carga hidráulica não é uma função linear de muitos parâmetros). Os parâmetros calibrados no modelo estacionário foram a condutividade hidráulica (K) e Condutância (C) dos rios. Duas zonas de condutividades hidráulicas diferentes foram definidas a partir de valores obtidos nos testes de aquífero, assim como de tentativas de melhor ajuste de cargas observadas (Figura 6). Devido à ausência de dados de condutividade hidráulica e geometria do leito dos rios, a Condutância foi estabelecida por calibração com valores variando entre $0,0058 \mathrm{~m}^{2} / \mathrm{s}$ a $1,5 \mathrm{~m}^{2} / \mathrm{s}$, baseado em Oliveira et al. (2019). A calibração estacionária utilizou como referencial as cargas hidráulicas dos PMs (cargas observadas) na data da perfuração (2015) comparadas aos valores das cargas calculadas. O parâmetro estatístico de calibração foi o erro médio quadrático normalizado (RMS).

Posteriormente foi feita a simulação em estado transiente para obtenção da distribuição das cargas hidráulicas e análise temporal dos componentes do balanço hídrico. Uma análise de sensibilidade em relação às taxas de rebaixamento observadas nos poços foi feita para os parâmetros porosidade efetiva $S_{y}(14-17 \%)$ e coeficiente de armazenamento específico $\mathrm{S}_{\mathrm{s}}\left(10^{-6}-10^{-41} / \mathrm{m}\right)$ na simulação transiente. Ressalta-se ainda que o topo do aquífero foi atribuído tomando como base o modelo digital de elevação a partir das imagens SRTM (Shuttle Radar Topography Mission), e a partir dele foram atribuídas as cargas hidráulicas dos poços de monitoramento.
A variabilidade espacial e temporal da recarga foi atribuida da seguinte forma: 1) Definição de 3 zonas, tomando como referência as isoietas e a distribuição das estações climatológicas; 2) Cálculo, para cada zona, dos valores médios mensais de chuva (P), evapotranspiração potencial (ETP) e real (ETR) pelo método de Thornthwaite (1955), utilizando planilhas elaboradas por Rolim et. al. (1998); 3) Estimativa das recargas mensais em cada zona a partir da diferença entre $P$ e ETR, levando-se em consideração que nos meses onde a ETR foi maior que $\mathrm{P}$ a recarga foi considerada nula. Considerase esta recarga como representativa de parte da água de chuva que infiltrou após evapotranspiração e considerando escoamento superficial não significativo, já que todo o topo plano do chapadão é uma área de recarga e os vales encaixados são considerados áreas de descarga.

A simulação transiente foi efetuada no solver WHS, considerando o aquífero livre, para o período de novembro de 2005 a julho de 2019, tendo 1630 "stress periods" de 30 dias (período de tempo em que todas as recargas são consideradas constantes), visando representar as variações sazonais. A escolha do início do período simulado deve-se aos períodos de observação das séries históricas da maioria das estações pluviométricas presentes na área, e o final do período simulado levou em consideração a disponibilização dos dados de NA dos PMs.

Foram feitas três simulações com fluxo transiente: i) considerando a recarga mensal; ii) considerando a recarga como média móvel dos últimos 12 meses e iii) considerando a recarga subtraída em $10 \%$.

\section{RESULTADOS E DISCUSSÕES}

\subsection{Rebaixamentos dos Nas}

O comportamento dos NAs mostra um declínio constante e aproximadamente uniforme entre os poços (Figura 5A), possivelmente relacionadas à diminuição da recarga e à explotação por poços. As flutuações de NA nos poços monitorados não acompanham a sazonalidade das chuvas e atribuímos isso aos NEs profundos (entre 38 e 120m) e às grandes distâncias dos poços às drenagens (entre 3,5 e 13km). Os PMs também mantêm uma distância mínima de $700 \mathrm{~m}$ de poços produtores de alta vazão, com exceção do PM55 (30m) que sofre interferências geradas pelo bombeamento de poços. 
Figura 5- (A) Gráficos de variação dos NAs normalizados nos PMs. (B) Zoneamento dos rebaixamentos anuais com PMs, poços cadastrados e pontos de outorga superficiais

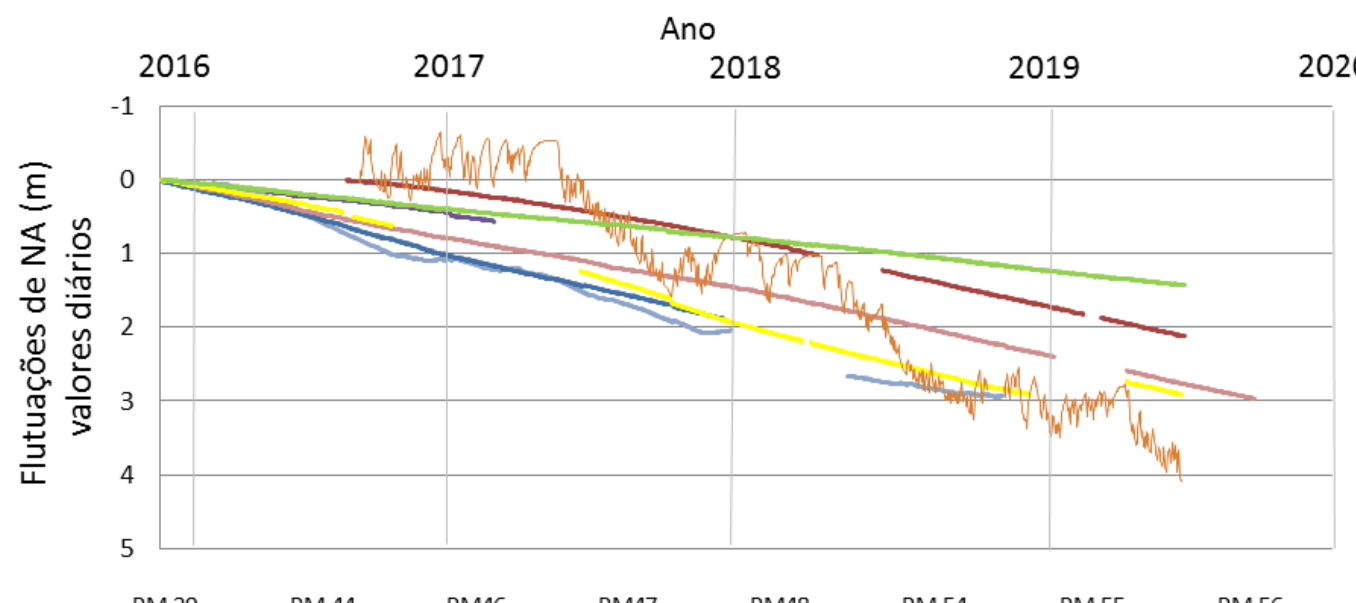

A-
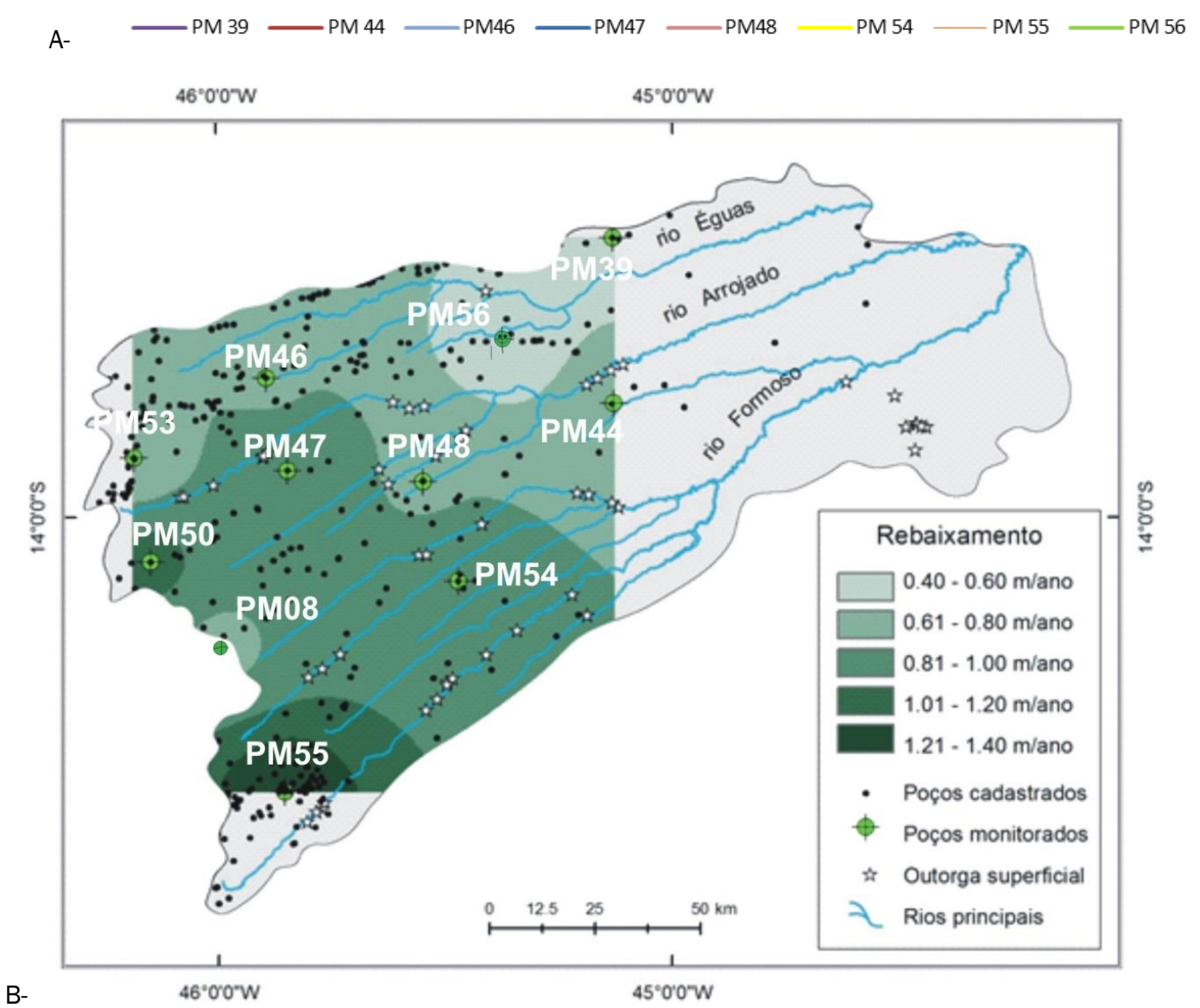

Os rebaixamentos anuais foram em média de $0,77 \mathrm{~m} /$ ano (variação de 0,4 a 1,1m/ano). Altas taxas de rebaixamento são verificadas na porção sudoeste da área, onde concentra-se um grande número de poços de alta vazão e também maior número de pontos de retirada de águas superficiais (Figura 5B).

\subsection{Análises Isotópicas}

A avaliação dos resultados das análises isotópicas para 180 e ${ }^{2} \mathrm{H}$ pode ser feita por meio de diagrama $\delta^{2} \mathrm{H}-\delta^{18} \mathrm{O}$ contendo a linha de água meteórica global (GMWL) e a linha meteórica local (LMWL)(GMWL; CRAIG, 1961). A GMWL é uma média de diversas curvas meteóricas locais e sua posição é controlada por processos como temperatura, latitude, altitude e trajetória das massas de ar sobre o continente (CLARK e FRITZ, 1997). As assinaturas isotópicas obtidas para as amostras de chuva local permitiram construir a LMWL, que apresenta um coeficiente angular de 9,85, e é considerada preliminar em função do pequeno número de amostras de chuvas. No diagrama $\delta^{2} \mathrm{H}-$ $\delta^{18} 0$ as águas subterrâneas amostradas posicionaram-se abaixo e paralelamente à LMWL indicando recarga por infiltração direta (ALLISON et al., 1982). Nota-se ainda que as assinaturas isotópicas das águas subterrâneas se aproximam às das águas de chuva mais depletadas em 180 (Figura 6A). Isso leva a possíveis interpretações: i) evidencia o efeito quantidade onde fortes chuvas são correlaciona- 
das a valores mais negativos de ${ }^{180}$ (DANSGAARD, 1964), resultando em recargas efetivas apenas em chuvas de grande volume e em concordância com os resultados de cálculo de recarga detalhadas abaixo; ii) condições climáticas distintas que deram origem às recargas, principalmente se considerarmos o posicionamento das amostras em relação à GMWL.

Assinaturas isotópicas de águas subterrâneas são também bons indicadores de áreas de recarga e padrões de mistura. Neste estudo, a similaridade das assinaturas entre águas superficiais e subterrâneas, para os dois períodos amostrados (Figura 6A) indica ainda a conexão hidráu- lica entre rios e aquífero. Isso será aplicado no modelo conceitual proposto, onde os rios são zonas de descarga do aquífero (ver item 4.3).

Da mesma forma, a similaridade das assinaturas isotópicas entre águas de poços rasos e profundos, captadas das formações Serra das Araras e Posse, respectivamente, ratifica a modelação do aquífero admitindo-se uma única unidade hidroestratigráfica. As águas do aquífero Urucuia são atribuídas como sendo essencialmente de águas de chuva, sem mistura com águas de aquíferos mais profundos.

Figura 6 - (A) Diagrama $\delta^{2} \mathrm{H}-\delta^{18} \mathrm{O}$ com assinaturas isotópicas de águas de poços, chuva e rio. (B) Diagrama ${ }^{3} \mathrm{H}-\delta^{18} \mathrm{O}$ dos poços amostrados. (C) Mapas de distribuição de $\delta^{18} \mathrm{O}$ de amostras de rio em período chuvoso (dezembro) e em período seco (setembro)

$\delta^{18} 0(\%$ VSMOW)

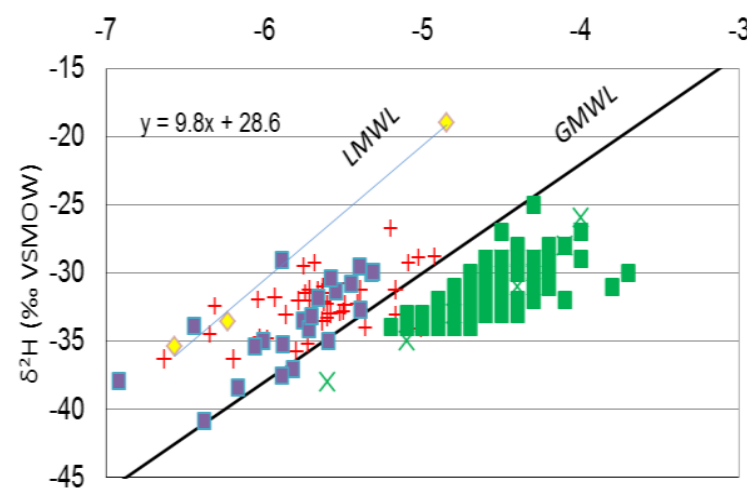

A)

+Rio (2016) XRio (2006) $\backsim$ Poços (2006) $\backsim \operatorname{Poços~(2016)~CHUVA~(2016)~}$

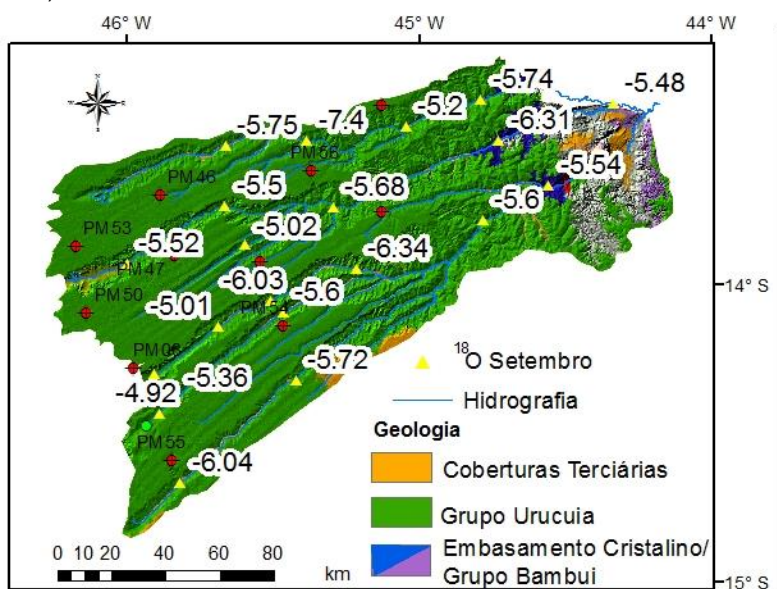

C)

Os valores de $\delta^{180}$ das águas dos rios amostradas durante o período de recessão (-5,65\%) é aproximadamente igual à média em épocas chuvosas $(-5,7 \%)$, representando, respectivamente, as médias das assinaturas isotópicas de águas subterrâneas (fluxo de base) e a média da mistura águas subterrâneas e chuvas, podendo evidenciar a pequena contribuição do escoamento superficial direto sobre a vazão dos rios. Estes valores são muito próximos da média das águas de poços (-5,88\%), evidenciando infiltração direta da chuva na recarga do aquífero, homogeneização espacial das águas superficiais e subterrâneas e a conexão rio/aquífero. A baixa variabilidade sazonal das
${ }^{3} \mathrm{H}(\mathrm{UT})$

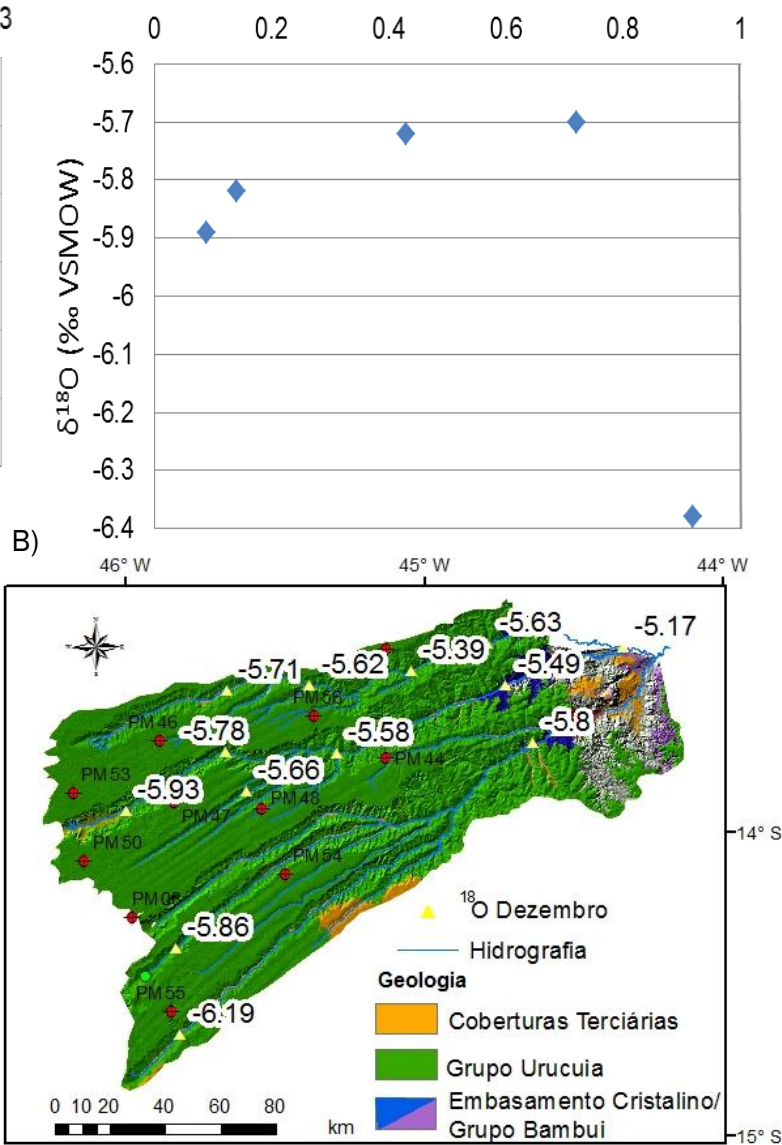

amostras de rio também evidencia a dominância da contribuição das águas subterrâneas sobre a contribuição das águas de chuvas no escoamento superficial. A resposta da variabilidade entre o $\delta^{180}$ das cabeceiras em relação à jusante no período chuvoso (dezembro) está relacionada à influência da evaporação sobre as águas superficiais ao longo do rio (Figura 6C).

$\mathrm{O}$ isótopo radioativo Trítio $\left({ }^{3} \mathrm{H}\right)$ possui um período de semidesintegração de 12,32anos (LUCAS e UNTERWEGER, 2000) e existe na atmosfera devido a causas naturais e antrópicas. A concentração do Trítio na água é expressa 
em UT (unidade de Trítio, que equivale a razão ${ }^{3} \mathrm{H} / \mathrm{H}$ ), onde em 1 UT a razão ${ }^{3} \mathrm{H} / \mathrm{H}$ equivale a 10-18. 0 Trítio nas águas subterrâneas variou entre $0,14 \pm 0,12$ e 0,92 $\pm 0,19 U T$, enquanto que nas águas superficiais, entre $0,32 \pm 0,14$ e $0,48 \pm 0,15 \mathrm{UT}$.

Verificou-se que os valores de Trítio nas águas superficiais são muito baixos e não correspondem aos valores de Trítio da chuva local, conforme valores de referência apresentados por Mazor (2003) de 5UT e das estações GNP de Salvador e Belo Horizonte, respectivamente de 3,2UT (dado de 1976) e 3,14UT ( dado de 2010). Sugere-se aqui que representariam o resultado da mistura de várias contribuições de recargas anuais do aquífero, sendo consideradas como anteriores a 1952 (<0,5UT), de acordo com a classificação semiquantitativa proposta por Mazor (2003).

Da mesma forma, as águas subterrâneas com Trítio menor que 0,5UT são igualmente consideradas como de recarga anterior a 1952, e os dois poços com valores um pouco mais elevados podem representar águas com maior tempo de residência, não tendo sido constatado relação com a profundidade dos filtros(Figura 6B). A determinação de um número maior de amostras de águas de poços tubulares seria fundamental para dirimir dúvidas e acrescentar informações de maior detalhe como possíveis zonas de semi-confinamento/confinamento, ou a localização de aquíferos suspensos.

Recomenda-se um número maior de análises de $3 \mathrm{H}$ e $18 \mathrm{O} /{ }^{2} \mathrm{H}$ em poços e operação de uma estação permanente de análises isotópicas de chuva $\left(180 /{ }^{2} \mathrm{H} \mathrm{e}{ }^{3} \mathrm{H}\right)$, no Oeste da Bahia, para melhor definir a LMWL e servir de referência em trabalhos futuros. Além disso, recomenda-se incluir metodologia de investigação para estimativa quantitativa do tempo de residência da água entre a recarga e a descarga a exemplo das relações ${ }^{3} \mathrm{H} /{ }^{3} \mathrm{He}$ e ${ }^{14} \mathrm{C} / \mathrm{PMC}$.

\subsection{Simulação de Fluxo}

O uso do modelo numérico neste estudo tem o caráter interpretativo, pois objetiva compreender e descrever a dinâmica de circulação da água no sistema aquífero e avaliar os componentes do $\mathrm{BH}$ do ponto de vista temporal e espacial.

Os gráficos da Figura 7 mostram a distribuição dos valores de P, ETR e ETP representativos das três zonas de recarga admitidas na simulação da área modelada. Dessa forma, os meses de efetiva recarga abrangeriam os períodos chuvosos que excedem a evapotranspiração real, que para o período analisado predominou entre outubro/novembro e fevereiro/março. 0 fato de considerar a recarga efetiva apenas nos períodos de chuva de grande volume é coerente com as conclusões da análise isotópica.

O parâmetro estatístico de calibração (RMS) em relação a cargas hidráulicas observadas foi de 4,59\% no estacionário e $6,27 \%$ no transiente. Foi utilizada ainda a comparação do fluxo de base com as vazões dos rios, além da disposição das curvas equipotenciais, tomando como base observações de campo (OLIVEIRA et al., 2019). Os parâmetros calibrados do modelo estacionário foram: condutividades $\mathrm{K} 1=1 \times 10^{-4} \mathrm{~m} / \mathrm{s}, \mathrm{K} 2=3 \times 10^{-4} \mathrm{~m} / \mathrm{s}$ e condutância $\mathrm{C}$ $=90000 \mathrm{~m}^{2} / \mathrm{d}$ (com a exceção de $24000 \mathrm{~m}^{2} / \mathrm{d}$ em apenas um afluente pequeno com influência em PM 46). No modelo transiente, os valores admitidos armazenamento específico e porosidade efetiva foram $S_{s}=2,6 \times 10^{-51} / \mathrm{m} \mathrm{e}_{\mathrm{y}}=$ 0,14 . Estes valores são próximos aos obtidos por CPRM (2008).

$\mathrm{Na}$ análise de sensibilidade verifica-se que o parâmetro mais sensível à calibração foi a condutividade hidráulica, com forte influência da recarga. Considera-se o erro residual como bastante razoável dado às limitações e simplificações intrínsecas à modelação matemática na área modelada: aproximações do modelo digital do terreno; simplificação do modelo conceitual e homogeneidade da geologia admitindo-se o caráter regional da pesquisa; generalizações do modelo em função da baixa densidade de dados hidrogeológicos; imprecisões na determinação da carga dos rios principalmente em função da dimensão das células na modelagem e a falta de dados de condutividade hidráulica vertical do leito dos rios.

As distribuições das linhas equipotenciais (Figura 8) para simulação estacionária e transiente são visualmente indistinguíveis.

Usando as recargas mensais obtidas da Figura 7, a simulação transiente mostra boa concordância de rebaixamentos (declínios de cargas hidráulicas) simulados e observados em termos de tendência interanual. Contudo, as cargas simuladas apresentam uma variabilidade sazonal que parece ser inexistente nas cargas reais observadas (Figura 9A). Por outro lado, percebe-se um bom ajuste do fluxo de base simulado à somatória das vazões médias dos rios tanto a nível interanual e sazonal (Figura 9C e 9D). 
Figura 7- Mapa esquemático com zonas de recarga e gráficos de precipitação (P), evapotranspiração potencial (ETP) e real (ETR) nas estações Rio do Meio (R1), Prata (R2) e Correntina (R3)

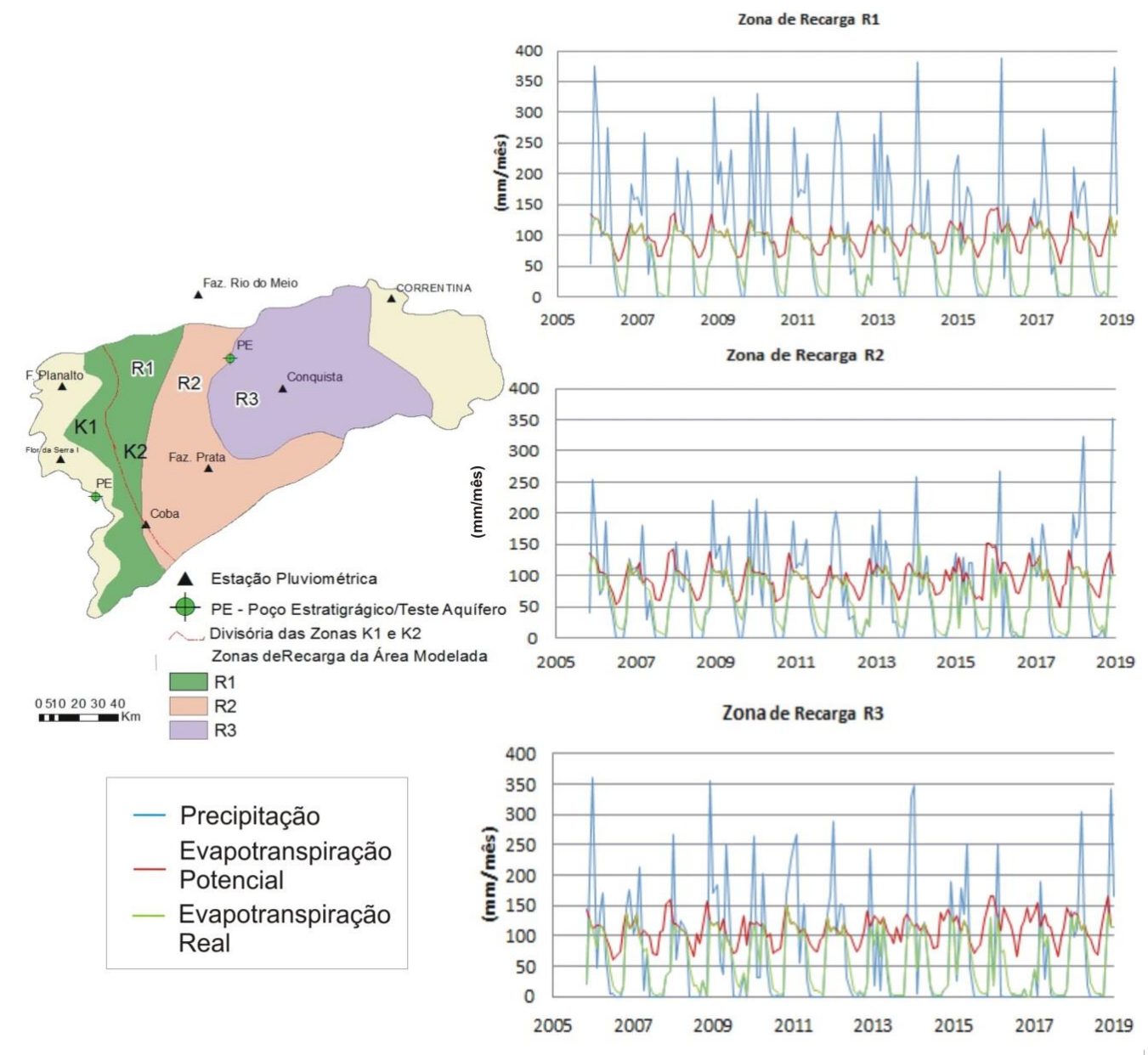

Figura 8- Mapa de distribuição de cargas com perfil A-B (indicando os vetores de fluxo e linhas equipotenciais) e gráfico de calibração de carga observada versus carga calculada estacionária
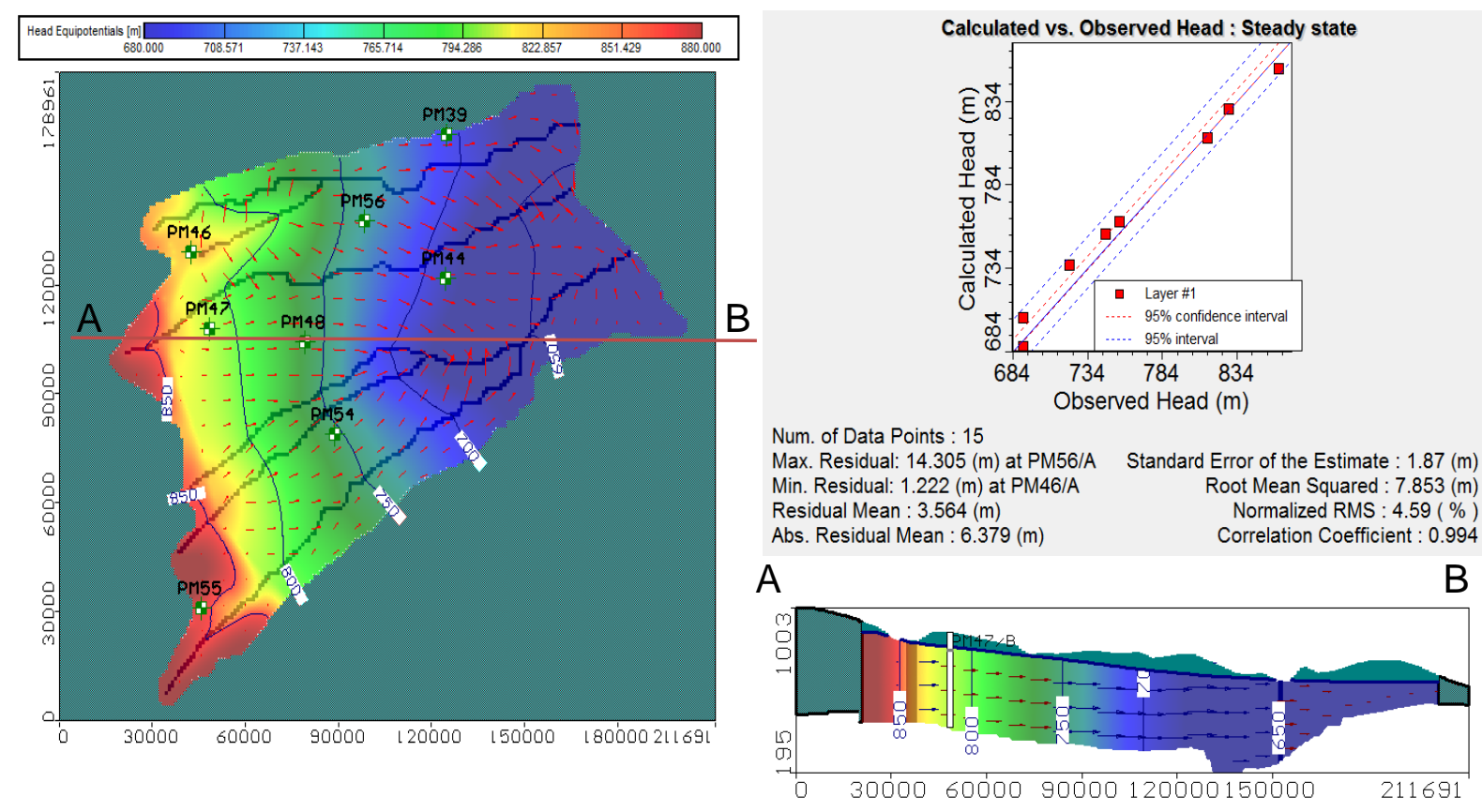
Figura 9 - (A) Gráfico de declínio de NA observados (linhas tracejadas) e calculados na simulação transiente com recargas mensais (linhas contínuas). (B) Gráfico de declínio de NA observados (linhas tracejadas) e calculados na simulação transiente com recargas mensais após aplicação da média móvel anual (linhas contínuas); (C) Variação temporal dos componentes do BH comparado à somatória das vazões médias dos rios (Figura 2B). (D) Variação temporal dos componentes do BH mensal (média móvel anual)
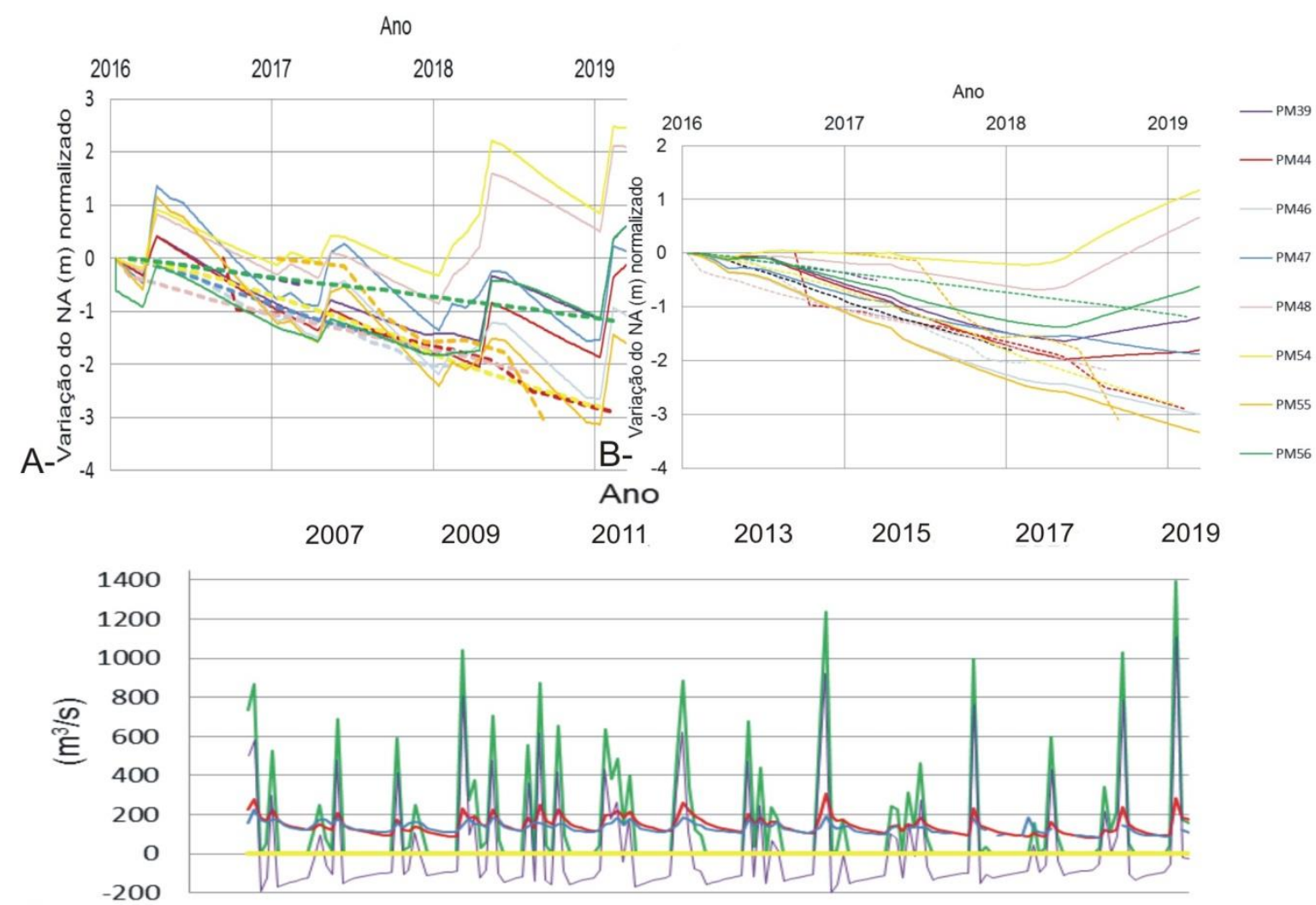

C-

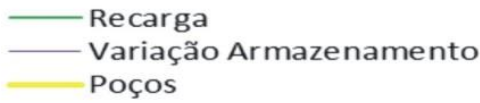

- Fluxo Base

- Soma Vazões Médias

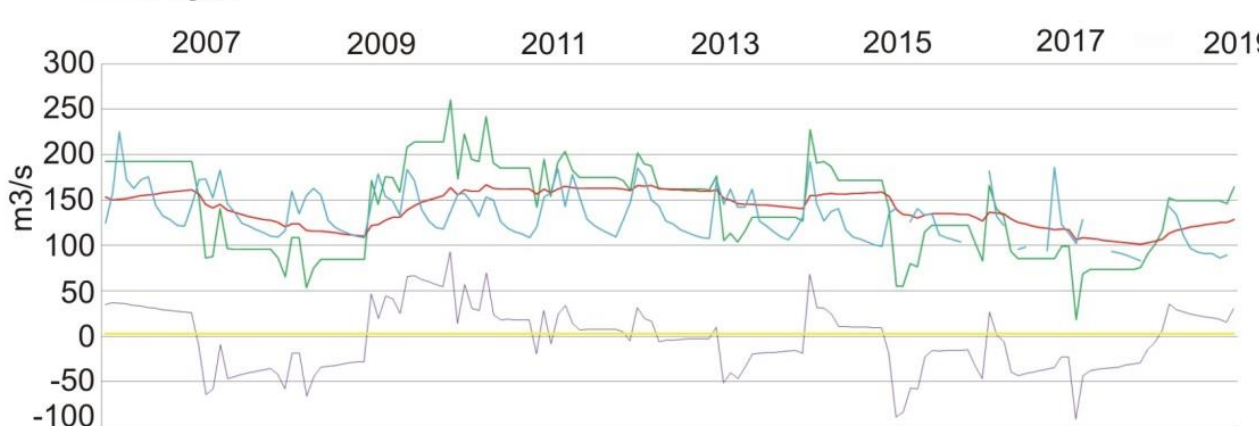

D-

$-100$

Constata-se uma aparente discrepância entre as sazonalidades nas observações de cargas hidráulicas (basicamente ausente) e vazões superficiais (muito regular e pronunciada) consideradas aqui como boas aproximações do fluxo de base real. De caráter hipotético, levantamos a possibilidade de um efeito significativo da espessura elevada da zona não saturada (ZNS) em grande parte do aquífero. Isso pode levar a uma diferença entre a recarga já calculada na superfície do solo (recarga superficial) e a recarga que chega ao lençol freático na profundidade (recarga freática) (e.g., Dickinson et al., 2014). Essa diferença não se manifestará na quantidade de recarga (ETR já foi considerada e não há mais perdas d’água na ZNS), mas na distribuição temporal da recarga efetivamente contribuindo ao volume de água armazenado no aquífero. Supõe-se, de forma simplificada, que um impulso de recarga superficial se dispersa ao atravessar a ZNS, fazendo com que parte desse impulso pode alcançar o lençol freático mais rápido, enquanto o restante demore meses ou até um ano. Em termos de modelagem matemática esta situação foi considerada por meio da conversão dos valores de recarga superficial, já calculados, a recargas freáticas usando a média móvel das recargas superficiais dos últimos 12 meses no modelo transiente (Figura 8B). Assim, eliminando-se a sazonalidade há melhor ajuste das cargas hidráulicas calculadas à situação real, no entanto 
com efeito de comprometimento significativo no ajuste às vazões reais.

A análise temporal da variação dos componentes do $\mathrm{BH}$ simulado neste cenário mostra que a recarga nos últimos anos vem sofrendo maior variabilidade anual e diminuiu significativamente entre 2012 e 2017 (Figura 9D). Isso se reflete na variação de armazenamento predominantemente negativa durante o período (NA em declínio) e na diminuição do fluxo de base dos rios. A partir de 2017, a recarga tem uma tendência a se recuperar. Contudo, se considerarmos que mesmo após o aumento das recargas em 2017 os NAs observados no aquífero se mantém em declínio, uma provável causa seria um subdimensionamento das descargas por poços no modelo.

Percebe-se que a contrastante espessura da ZNS nas áreas de vale e nas áreas do Chapadão responde pela contrastante sazonalidade de cargas hidráulicas e fluxo de base. Próximo às drenagens, a difereça entre recarga superficial e freática torna-se mínima (como ocorre no PM20, localizado na bacia do rio Grande-aquífero UrucuiaFigura 10) e, nas áreas no chapadão, mais distantes dos rios, a sazonalidade na elevação do nível freático é efetivamente removida pela propagação da recarga através da ZNS (Figura 5A).

Figura 10 - Variação de NA subterrânea (azul) e da precipitação (verde) no PM20 localizado a aproximadamente 85km do PM32, fora da área de estudo, ver Figura 1

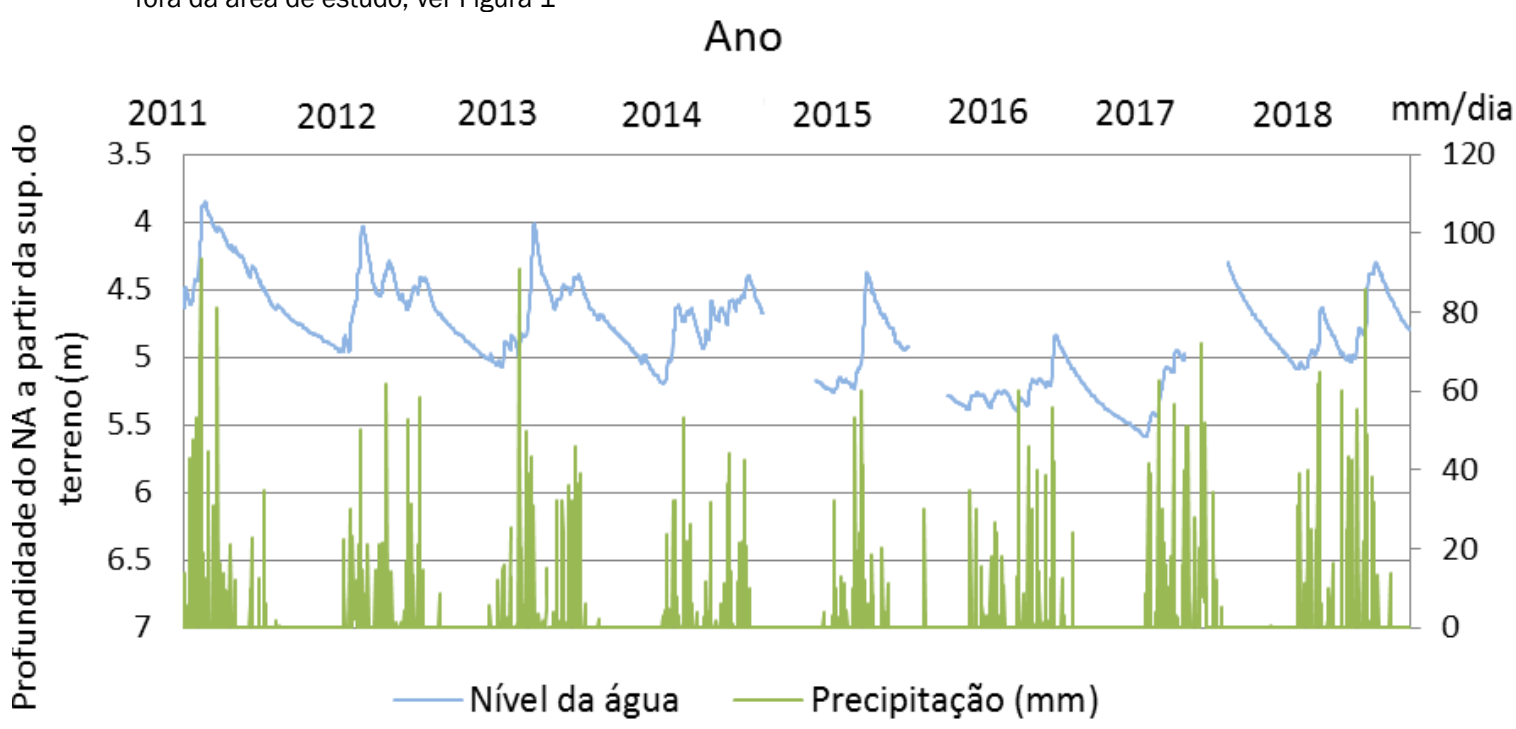

Para investigar ainda a dinâmica do comportamento hidráulico do aquífero, simulamos as respostas degrau a uma diminuição súbita de $10 \%$ na recarga, com iguais condições de contorno e admitindo-se vazão de poços constante. 0 sistema se reequilibraria a partir de aproximadamente uma década, destacando-se o efeito sobre o componente fluxo de base (Figura 11A), e redução do armazenamento na fase transiente (Figura 11B). Já nas respostas das cargas hidráulicas, observa-se dois tipos gerais de comportamentos (Figura $11 \mathrm{C}$ ). Os maiores efeitos da redução de recarga sobre os rebaixamentos de NAs em termos de magnitude e tempo para reequilíbrio ocorrem sobre os poços da porção oriental (PMs $46,47,48,55)$, exceto para o poço 54 . Na porção ocidental (PMs 39,44,56) tanto os rebaixamentos finais quanto a duração do período transiente são menores. Isso pode indicar uma maior sensibilidade da zona oriental a mudanças climáticas futuras em termos de disponibilidade de água subterrânea. 
Figura 11 - Respostas degrau a uma redução em 10\% da recarga com extração dos poços constante. (A) Fluxo de base, (B) Variação de armazenamento e (C) Cargas hidráulicas
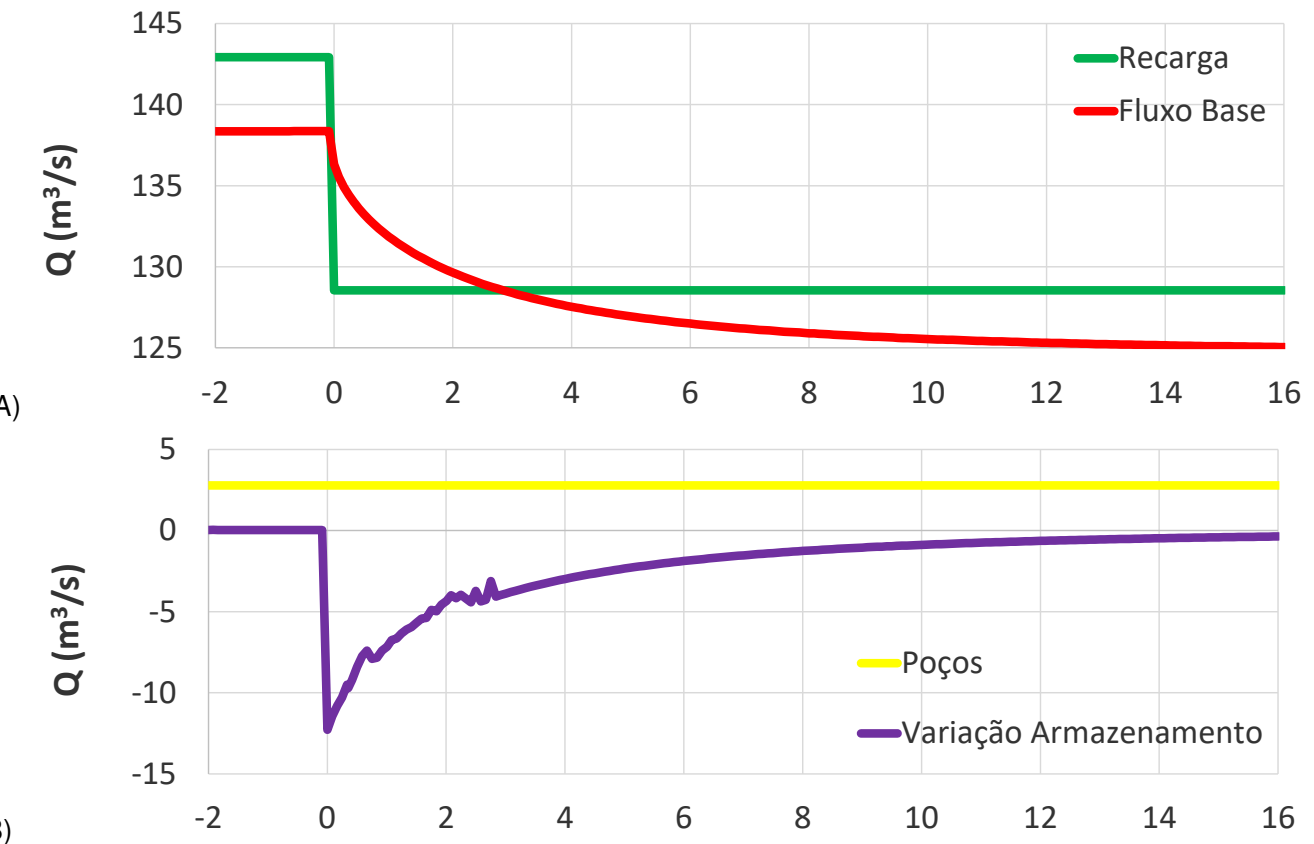

B)

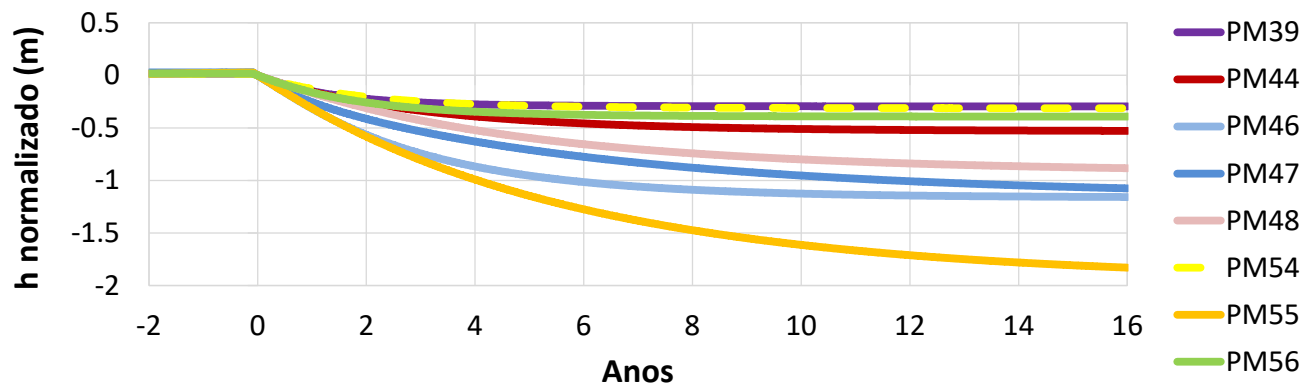

C)

Verifica-se, portanto rebaixamentos de até 1,8 metros para a redução aplicada de 10\% na recarga. ANA (2017) simulou em regime permanente um cenário de possível mudança climática considerando redução de $21 \%$ na recarga e obteve rebaixamentos superiores a $3 \mathrm{~m}$ na potenciometria da bacia do rio Corrente, para o período 2021 2050.

\section{CONCLUSÃO}

A análise temporal dos componentes do $\mathrm{BH}$ a partir da simulação transiente permitiu reconhecer a dinâmica da água no sistema hídrico em uma porção do aquífero Urucuia. A interpretação isotópica ratifica o modelo conceitual proposto e contribui no entendimento da composição da recarga. As oscilações de NA subterrânea, com tendência de declínio constante provavelmente iniciou-se em 2012 e são atribuídas ao efeito da variabilidade na recarga nos últimos 7 anos e à explotação do aquífero. 0 melhor ajuste da simulação, utilizando-se da média móvel da recarga freática sugere uma diferenciação temporal entre esta e a recarga efetiva. Dessa forma, a sazonalidade na elevação do nível freático é efetivamente removida pela propagação da recarga nas áreas de maior espessura da ZNS.

A simulação transiente permitiu ainda verificar a dinâmica do comportamento hidráulico do sistema hídrico, onde a diminuição súbita de 10\% na recarga, em um cenário futuro hipotético, necessitaria de no mínimo uma década para se reequilibrar.

Recomendamos, além da continuidade das análises isotópicas sistemáticas das águas de chuva, a manutenção da rede de monitoramento hidroclimatológico e hidrogeológica e a instalação de hidrômetros nos poços produtivos de alta vazão visando aprimorar as ferramentas de modelagem e subsidiar a implantação de mecanismos de gestão mais flexíveis e dinâmicos.

\section{AGRADECIMENTOS}

Agradecemos ao Serviço Geológico do Brasil pelo apoio a esta pesquisa. 


\section{REFERÊNCIAS}

ANA. Agência Nacional de Águas (Brasil). Sistema Nacional de Informações sobre Recursos Hídricos. Brasília, 2020. Disponível em: http://www.snirh.gov.br/hidroweb/publico/medicoes historicas_abas.jsf. Accesso em: 03 Mar. 2020.

ANA. Agência Nacional de Águas (Brasil). Estudos hidrogeológicos e de vulnerabilidade do sistema aquífero urucuia e proposição de modelo de gestão integrada e compartilhada: relatório final. Consórcio Engecorps - Walm - Brasília. 3 Volumes. 2017.

ALLISON, G.B. Relationship between ${ }^{18} \mathrm{O}$ and Deuterium in water in sand columns undergoing evaporation. Journal of Hydrology, v. 55, n. $1 / 4$, p. 163-169, 1982. https://doi.org/10.1016/00221694(82)90127-5

CHAMINÉ, H.I. Water resources meet sustainability: new trends in environmental hydrogeology and groundwater engineering. Environmental Earth Science, v. 73, p. 2513-2520, 2015. https://doi.org/10.1007/s12665-014-3986-y

CLARK, I.D.; FRITZ, P. Environmental isotopes in hydrogeology. New York: CRC Press, 1997. 328p.

CPRM - Serviço Geológico do Brasil. (Brasil). Hidrogeologia do aquífero Urucuia: Bacias dos Rios Arrojado e Formoso, Bahia. Brasília: CPRM, 2008. 1 CD-ROM. Projeto Comportamento das Bacias Sedimentares da Região Semi-Árida do Nordeste Brasileiro.

CPRM - Serviço Geológico do Brasil. (Brasil). Aquífero Urucuia: caracterização hidrológica com base em dados secundários. 219.Disponível em: http://rigeo.cprm.gov.br/jspui/handle/doc/20922

CRAIG, H.C. Isotopic variations in meteoric waters. Science, v. 133, p. 1702-1703, 1961.

DANSGAARD, W. Stable isotopes in precipitation. Tellus, v. 16, n. 4 , p. 436-468, jan. 1964. https://doi.org/10.3402/tellusa.v16i4.8993

DICKINSON, J.E; FERRÉ, T.P.A.; BAKKER, M.; CROMPTON, B. 2014. A Screening Tool for Delineating Subregions of Steady Recharge within Groundwater Models. Vadose Zone Journal, v. 13, n. 6, p.1-15.

FETTER, C.W. Applied hydrogeology. 4.ed. New Jersey: Prentice Hall, 2001. https://doi.org/10.2136/vzj2013.10.0184

FISHER, J.C.; BARTOLINO, J.R.; WYLIE, A.H.; SUKOW, J.; MCVAY, M MODFLOW-USG: model of groundwater flow in the Wood River Valley aquifer system in Blaine County, Idaho. Reston, VA, USA:USGS, 2016. https://doi.org/10.3133/sir20165080

FREEZE, R.A.; CHERRY, J.A. Groundwater. New Jersey: Pretice Hall, 1979. 604p.

GASPAR, M.T.P. Sistema Aquífero Urucuia: caracterização regional e propostas de gestão. 2006. 158f. Tese (Doutorado) - Instituto de Geociências, UnB, Brasília, 2006.

GRÖNING, M., LUTZ, H.O., ROLLER-LUTZ, Z., KRALIK, M. , GOURCY, L. , PÖLTENSTEIN, .L.A Simple rain collector preventing water reevaporation dedicated for $\delta^{18} \mathrm{O}$ and $\delta^{2} \mathrm{H}$ analysis of cumulative precipitation samples. Journal of Hydrology, v. 448, p. 195-200, 2012.

GUZMAN, S.; PAZ, J.; TAGERT, M. The Use of NARXNeural networks to forecast daily groundwater levels. Water Resources Management, v. 31, n. 5, p. 1591-1603, 2017. https://doi.org/10.1016/i.jhydrol.2012.04.041

HARBAUGH, A.W. MODFLOW-2005, the U.S. Geological survey modular ground-water model-the ground-water flow process. U.S. Geological Survey Techniques and Methods 6-A16. Reston, VA: U.S. USGS, 2005. (USGS Open file Report). https://doi.org/10.3133/tm6A16
LE BROCQUE, A.F.; KATH, J.; REARDON-SMITH, K. Chronic groundwater decline: a multi-decadal analysis of groundwater trends under extreme climate cycles. Journal of Hydrology, v. 561, p. 976986, 2018. https://doi.org/10.1016/j.jhydrol.2018.04.059

LUCAS, L.L.; UNTERWEGER, M.P. Comprehensive review an halflife of Tritium. Journal of Research of the National Institute of Standards and Technology, v. 105, p. 54, 2000. https://doi.org/10.6028/jres.105.043

MAIMONE, M. Defining and managing sustainable yield. Ground Water, v, 42, n. 6, p. 809-814, 2004. https://doi.org/10.1111/j.1745-6584.2004.tb02739.x

MAZOR, E. Chemical and isotopic groundwater hydrology. 3.ed. New York: Marcel Dekker, 2003. 352p. https://doi.org/10.1201/9780203912959

MOHANTY, S.; JHA, M.K.; KUMAR, A. Comparative evaluation of numerical model and artificial neural network for simulating groundwater flow in Kathajodi-Surua Inter-basin of Odisha, India. Journal of Hydrology, v. 495, p. 38-51, 2013. https://doi.org/10.1016/i.jhydrol.2013.04.041

OLIVEIRA, L.T.; KLAMMLER, H.; LEAL, L.R.B., GRISSOLIA. E.M. Analysis of the long-term effects of groundwater extraction on the water balance in part of the Urucuia Aquifer System in Bahia - Brazil. Revista Ambiente e Água, v. 14, n. 6, 2019. https://doi.org/10.4136/ambi-agua.2390

OU, G.; MUNOZ-ARRIOLA, F.; UDEN, D.R.; MARTIN, D.; ALLEN, C.R.; SHANK, N. Climate change implications for irrigation and groundwater in the Republican River Basin, USA.(Report). Climatic Change, v. 151, n. 2, p. 303 14, 2018. https://doi.org/10.1007/s10584-018-2278-z

POUSA, R.; COSTA, M. H.; PIMENTA, F. M.; FONTES, V. C.; BRITO, V. F. A.; CASTRO, M. Climate change and intensive irrigation growth in western Bahia, Brazil: the urgent need for hydroclimatic monitoring. Water, v. 11, n. 5, p. 933, 2019. https://doi.org/10.3390/w11050933

ROLIM, G.S.; SENTELHAS, P.C.; BARBIERI, V. Planilhas no ambiente Excel para os cálculos de balanços hídricos: normal, sequencial, de cultura e de produtividade real e potencial. Revista Brasileira de Agrometeorologia, v. 6, n. 1, p. 133-137, 1998.

SERVIÇO GEOLÓGICO DO BRASIL - CPRM. Sistema de Informações de Águas Subterrâneas - SIAGAS. Brasília: SBG/CPRM, 2020. Disponivel em http://siagasweb.cprm.gov.br/layout/. Acesso em: mar. 2020

THEIS, C.V. The source of water derived from wells: essential factors controlling the response of an aquifer to development. Civil Engineering, v. 10, p. 277-280, 1940.

THORNTHWAITE, C.W.; MATHER, J.R. The water balance. publications in climatology. Drexel Institute of Technology, v. 8, n. 1. 1955.

WADA, Y. Modeling groundwater depletion at regional and global scales: present state and future prospects. Survey Geophysics, v. 37, p. 419-451, 2016. https://doi.org/10.1007/s10712-0159347-x

WERNER, A.D.; ZHANG, Q.; XUE, L.; SMERDON, B.D.; LI, X.; ZHU, X.; YU, L.; LI, L. An Initial inventory and indexation of groundwater mega-depletion cases. Water Resources Management, v. 27, n. 2, p. 507-533, 2013. https://doi.org/10.1007/s11269-012$0199-6$

ZHOU, Y. A Critical review of goundwater budget myth, safe yield and sustainability. Journal of Hydrology, v. 370, n. 1-4, p. 207213, 2009. https://doi.org/10.1016/i.jhydrol.2009.03.009 